Check for updates

Cite this: RSC Adv., 2019, 9, 22106

\title{
Utilization of 7-chloro-4-nitrobenzo-2-oxa-1,3- diazole (NBD-Cl) for spectrochemical determination of L-ornithine: a multivariate optimization-assisted approach
}

\begin{abstract}
Hend Aly, (D) Ahmed S. El-Shafie (D) and Marwa El-Azazy (DD*
A simple and highly sensitive univariate calibration strategy based on ultraviolet-visible (UV-Vis) absorption spectroscopy and assisted by multivariate screening and optimization was utilized for the determination of L-ornithine (L-ORN) as such and in the alimentary supplements. L-ORN, an OTC marketed amino acid, is widely used for bodybuilding and might be abused by athletes. A nucleophilic substitution reaction using 7-chloro-4-nitrobenzo-2-oxa-1,3-diazole (NBD-Cl) was the basis of the current investigation. PlackettBurman design (PBD) and a response surface optimizer as screening and fine-tuning strategies, respectively, were instigated. Four numerical variables, reaction time (RT), temperature (Temp), $\mathrm{pH}$ and reagent volume (RV), and one categorical variable, the diluting solvent (DS), were considered. Absorbance of the yellow-colored adduct at $469 \mathrm{~nm}$ was the response studied. Pareto analysis, along with analysis of variance (ANOVA) were used to ascertain the significant variables (screening phase) and their domains (optimization phase). Response transformation and stepwise analysis were employed when necessary. Probability, cube and individual value plots were used to get an insight into the statistical impact of the variables tested. Multiple responses' optimization was performed using Derringer's function. Calibration curves were linear in the range of $5-50 \mu \mathrm{g} \mathrm{mL}^{-1}$. Job's technique of continuous variation showed that the stoichiometric ratio is $2: 1$ (NBD-Cl:L-ORN). The proposed technique was successfully applied to the dietary supplements of L-ORN, inferring no interference from adjuvants and

excipients. Analytical performance of this technique was validated conforming to the ICH standards.
\end{abstract}

Received 3rd May 2019

Accepted 1st July 2019

DOI: $10.1039 / c 9 r a 03311 d$

rsc.li/rsc-advances

\section{Introduction}

Dietary supplements are a broad term that includes a wide range of products that are administered based on a prescription or over-the-counter (ОTC), due to their health impacts. Worldwide sales of dietary supplements are going through a hasty growth. This dramatic progression together with the overall absence of an obligation to pass operative directions and regulations makes this market more liable to deceitful procedures, possible adulteration, and a greater incidence of safety and quality concerns. Alimentary supplements, especially those stemming from natural origins, are the most commonly used. On the one hand, because they are natural, this is a magic word that attracts customers who think that there will be no sideeffects. On the other hand, since they are natural, they are available at low prices. ${ }^{1,2}$ The availability of sound, reliable, and sensitive techniques for the determination of these compounds per se and in the marketed formulations then becomes crucial. Moreover, understanding the nature (chemical and physical) of

Department of Chemistry and Earth Science, College of Arts and Sciences, Qatar University, Doha 2713, Qatar. E-mail: marwasaid@qu.edu.qa these compounds before developing an analytical technique is an important step.

L-Ornithine (L-ORN), chemically known as (+)-(S)-2,5-diaminovaleric acid, is shown in Scheme 1. As a non-essential amino acid, it is not necessary for L-ORN to be included in humans' diets as it is already synthesized in their bodies. L-ORN is a non-proteinogenic amino acid, which is not coded naturally in the DNA, and is produced as an intermediate component of the urea cycle. $.^{3-5} \mathrm{~L}-\mathrm{ORN}$ is one of the OTC dietary supplements that is commonly used by athletes where it is thought to have a role in increasing the mass of the muscles, as well as an ability to enhance the performance through increasing strength, the production of Human Growth Hormone (HGH) and improving fat metabolism. Moreover, L-ORN has a main role in burning up<smiles>NCCC[C@H](N)C(=O)O</smiles>

Scheme 1 L-Ornithine monohydrochloride (L-ORN). 
excess fat in the body and is used for enhancing the workability of the immune system. ${ }^{3-7}$

Several techniques were reported in the literature for the determination of L-ORN. These techniques are mainly chromatography based..$^{8-10}$ The limitations of these techniques could be summarized as univariate-based, expensive, time consuming and the requirement for well-trained staff. Spectrophotometric and spectrofluorometric analyses were also used to determine L-ORN following the formation of a colored derivative since L-ORN does not have a chromophore. ${ }^{11}$ The reported study was multivariate analysis (MVA) based and employed the Hantzsch condensation reaction. The reported approach, however, could determine L-ORN in a limited concentration range.

In this study, the determination of ${ }_{\mathrm{L}}-\mathrm{ORN}$ in its both forms (per se and supplements) will be performed through nucleophilic substitution reaction using 7-chloro-4-nitrobenzo-2-oxa1,3-diazole (NBD-Cl), Scheme 2. NBD-Cl is a commonly used reagent for the quantitative determination of thiols and amines. ${ }^{12-15}$

As mentioned, the literature shows that the majority of techniques reported to determine L-ORN were univariate analysis-based (UVA) implying that each variable was treated as a separate entity, an issue that does not provide any idea about the interaction between the factors. Moreover, each variable investigation would require a large number of experiments to be performed. On the contrary, multivariate analysis (MVA) which is used in this study has the ability to overcome these limitations. Furthermore, the results of MVA would provide an idea about the relationship between all the factors that might affect the reaction with a high degree of inevitability. ${ }^{\mathbf{1 6}}$

Plackett-Burman design (PBD) is the screening design that is used in this study. This design is a type of fractional factorial design. The main advantage of using the PBD is that it can investigate a large number of factors with the least number of experiments, as it ignores completely the interactions between the factors. Moreover, PBD is commonly used in the pharmaceutical industry because of its economical and effectual procedures. ${ }^{17-19}$ Four numerical variables that are thought to have an impact on the reaction, $\mathrm{pH}$, the temperature of the reaction (Temp), volume of the reagent (RV) and the reaction time (RT), plus one categorical factor, the diluting solvent (DS), will be considered. ${ }^{11}$

The current study aims to develop a simple, sensitive and accurate analytical method based on UV-Vis absorption spectroscopy and 7-chloro-4-nitrobenzo-2-oxa-1,3-diazole (NBD-Cl) for determining $\mathrm{L}-\mathrm{ORN}$ in its pure form and in dietary supplements<smiles>O=[N+]([O-])c1ccc(Cl)c2nonc12</smiles>

Scheme 2 7-Chloro-4-nitrobenzo-2-oxa-1,3-diazole.
Table 1 Screened numerical and categorical variables for PBD for the nucleophilic substitution reaction

\begin{tabular}{llll}
\hline Variables & Low $(-1)$ & Center point $(0)$ & High $(+1)$ \\
\hline Numerical variables & & & \\
pH, $A$ & 7 & 9 & 11 \\
Temperature $\left({ }^{\circ} \mathrm{C}\right), B$ & 55 & 67.5 & 80 \\
Reaction time $(\mathrm{min}), C$ & 5 & 30 & 35 \\
Reagent volume $(\mathrm{mL}), D$ & 0.2 & 1.1 & 2 \\
\hline
\end{tabular}

Categorical variables

Diluting solvent, E Distilled water (DW) Methanol (MeOH)

with the lowest possible experimental efforts, implementing PBD as a multivariate optimization approach. To the best of our knowledge, the method we are proposing herein has not been reported before. The proposed univariate calibration strategy assisted by multivariate screening and optimization can be implemented as a quality control approach for the routine analysis of L-ORN especially in developing countries where sophisticated techniques like chromatography might not be available.

\section{Experimental}

\subsection{Instruments and software}

A UV-Vis spectrophotometer (Agilent diode-array, USA) with $10 \mathrm{~mm}$ matched quartz cells was used to measure the absorbance of the samples. Laboratory water bath (MLV, Salvis AG Emmenbruck, Germany) was used to heat the prepared samples to the

Table 2 Experimental setup and the obtained responses using $\mathrm{PBD}^{a}$

\begin{tabular}{|c|c|c|c|c|c|c|c|c|}
\hline \multirow[b]{2}{*}{ Run no } & \multicolumn{5}{|c|}{ Variables } & \multicolumn{3}{|c|}{ Response } \\
\hline & $A$ & $B$ & $C$ & $D$ & $\mathrm{E}$ & $Y 1^{*}$ & $Y 1^{* *}$ & $Y 1^{* * *}$ \\
\hline 01 & 9 & 67.5 & 20 & 1.1 & Water & 0.0021 & 0.0521 & 0.0037 \\
\hline 02 & 11 & 80 & 5 & 2.0 & Methanol & 0.1040 & 0.1451 & 0.1691 \\
\hline 03 & 7 & 55 & 35 & 2.0 & Methanol & 0.2440 & 0.3476 & 0.2880 \\
\hline 04 & 7 & 55 & 5 & 2.0 & Methanol & 0.0554 & 0.1378 & 0.0814 \\
\hline 05 & 7 & 80 & 35 & 0.2 & Methanol & 0.1966 & 0.1916 & 0.1036 \\
\hline 06 & 7 & 80 & 35 & 2.0 & Water & 0.7346 & 0.5332 & 0.9830 \\
\hline 07 & 7 & 80 & 5 & 0.2 & Water & 0.0391 & 0.0776 & 0.0264 \\
\hline 08 & 7 & 55 & 5 & 0.2 & Water & 0.0058 & 0.0086 & 0.0070 \\
\hline 09 & 9 & 67.5 & 20 & 1.1 & Methanol & 0.0040 & 0.0043 & 0.0041 \\
\hline 10 & 11 & 80 & 5 & 2.0 & Water & 0.1871 & 0.2408 & 0.1526 \\
\hline 11 & 11 & 55 & 35 & 0.2 & Water & 0.0058 & 0.1148 & 0.0136 \\
\hline 12 & 9 & 67.5 & 20 & 1.1 & Water & 0.0045 & 0.0521 & 0.0037 \\
\hline 13 & 11 & 55 & 35 & 2.0 & Water & 0.0890 & 0.3607 & 0.1428 \\
\hline 14 & 11 & 55 & 5 & 0.2 & Methanol & 0.0068 & 0.0191 & 0.0043 \\
\hline 15 & 9 & 67.5 & 20 & 1.1 & Methanol & 0.0063 & 0.0436 & 0.0041 \\
\hline 16 & 11 & 80 & 35 & 0.2 & Methanol & 0.0360 & 0.1090 & 0.0569 \\
\hline
\end{tabular}

${ }^{a}(\mathrm{pH},(A))$, (temperature, Temp $\left.(B),{ }^{\circ} \mathrm{C}\right)$, (reaction time, RT, $(C) \mathrm{min}$ ), (reagent volume, RV, $(D) \mathrm{mL}$ ), (solvent type, DS, (E) methanol or distilled water), absorbance (Abs at $469 \mathrm{~nm}$ ). *Experimental values for $Y 1$. **Predicted values before response transformation: $Y 1 * *=-0.176$ $-0.0207 \mathrm{pH}+0.00360 \mathrm{Temp}+0.00699 \mathrm{RT}+0.1366$ volume of NBD-Cl $0.0479 \mathrm{DS}-0.1670 \mathrm{Ct}$ Pt. ***Predicted values after response transformation: $\ln \left(Y 1^{* * *}\right)=-7.26-0.1499 \mathrm{pH}+0.0532 \mathrm{Temp}+$ $0.0421 \mathrm{RT}+1.307$ volume of NBD-Cl + 0.051 DS $-2.801 \mathrm{Ct}$ Pt. 


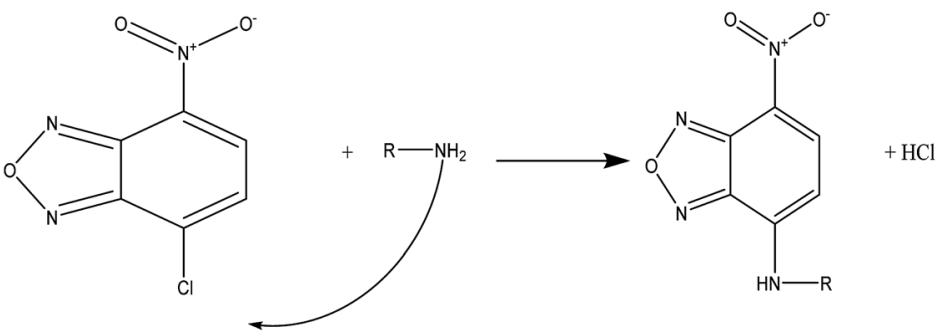

Scheme 3 Reaction of NBD-Cl with primary amines.

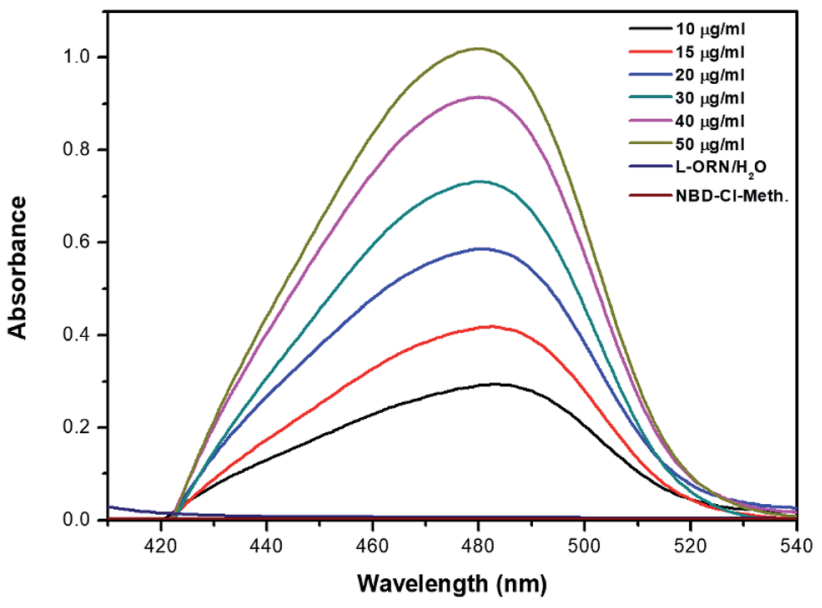

Fig. 1 Absorption spectrum for the reaction of L-ORN with NBD-Cl under optimal conditions. The optimal conditions are Temp $=80^{\circ} \mathrm{C}$, $\mathrm{pH}=7, \mathrm{RT}=35 \mathrm{~min}$, and $\mathrm{RV}=2 \mathrm{~mL}$.

temperature needed for the reaction. A pH meter (Jenway, UK) was used to adjust the buffers that were prepared, and an analytical balance was used to measure the mass that was needed.

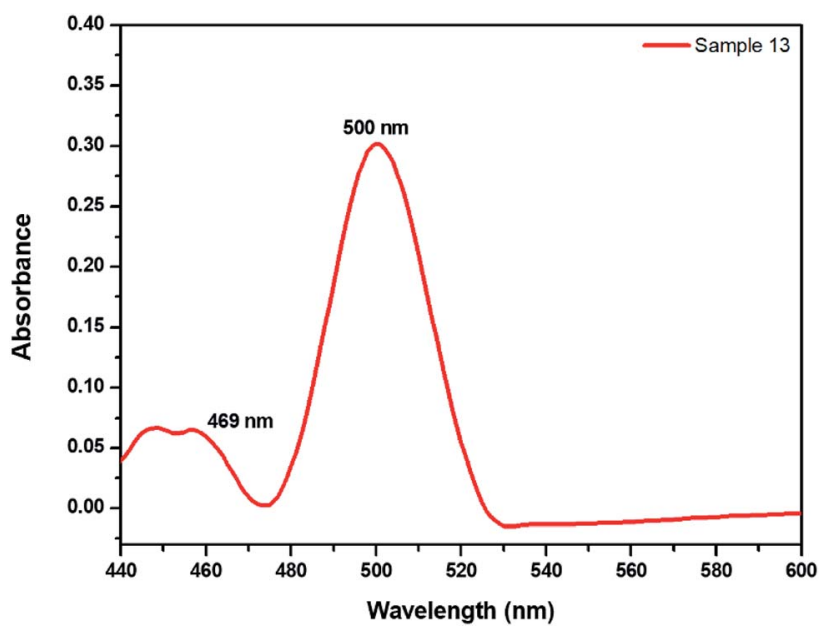

Fig. 2 Absorption spectrum for sample 13 (Table 2) showing the formation of a second peak at $500 \mathrm{~nm}$ after the decomposition of the peak at $469 \mathrm{~nm}$.

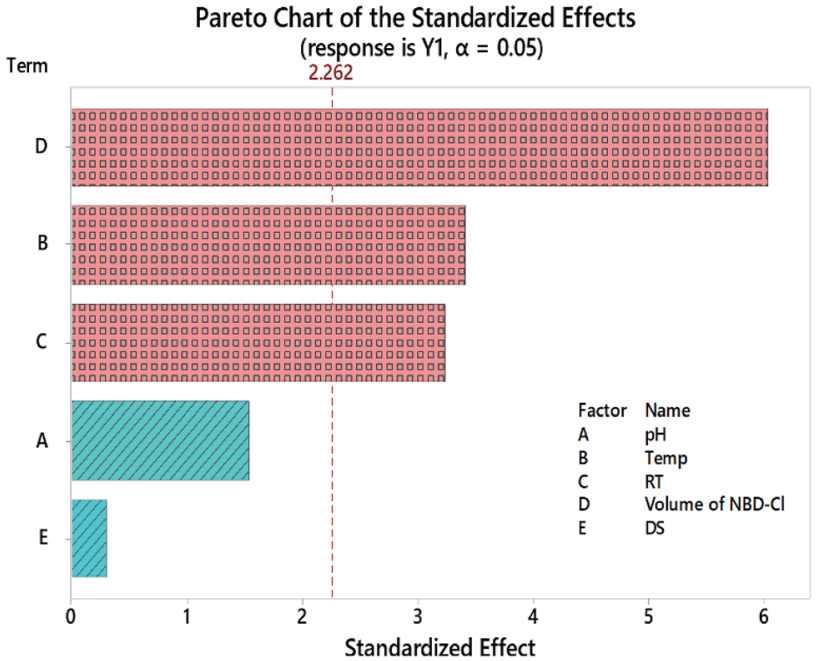

Fig. 3 Pareto chart of standardized effects for $Y 1$ following the response transformation.

Minitab®18 software was purchased from Minitab Inc., State College, Pennsylvania, USA. The software was used to make the list of experiments according to the selected design.

\subsection{Materials}

L-Ornithine monohydrochloride (L-ORN), NBD-Cl, methanol, sodium hydroxide, sodium tetraborate-10-hydrate $\left(\mathrm{Na}_{2} \mathrm{~B}_{4} \mathrm{O}_{7^{-}}\right.$ $\cdot 10 \mathrm{H}_{2} \mathrm{O}$ ) and hydrochloric acid were all purchased from Sigma-

Table 3 Analysis of variance (ANOVA) for transformed response ${ }^{a}$

\begin{tabular}{lrrlll}
\hline Source & DF & \multicolumn{1}{c}{ Adj SS } & Adj MS & $F$-value & $P$-value \\
\hline Model & 6 & 51.3504 & 8.5584 & 18.80 & 0.000 \\
Linear & 5 & 27.8093 & 5.5619 & 12.22 & 0.001 \\
pH & 1 & 1.0780 & 1.0780 & 2.37 & 0.158 \\
Temp & 1 & 5.3026 & 5.3026 & 11.65 & 0.008 \\
RT & 1 & 4.7855 & 4.7855 & 10.51 & 0.010 \\
RV & 1 & 16.6014 & 16.6014 & 36.46 & 0.000 \\
DS & 1 & 0.0417 & 0.0417 & 0.09 & 0.769 \\
Curvature & 1 & 23.5411 & 23.5411 & 51.70 & 0.000 \\
Error & 9 & 4.0979 & 0.4553 & & \\
Lack-of-fit & 7 & 3.7043 & 0.5292 & 2.69 & 0.298 \\
Pure error & 2 & 0.3936 & 0.1968 & & \\
Total & 15 & 55.4483 & & &
\end{tabular}

${ }^{a} \mathrm{DF}$ is degrees of freedom; SS is sum of squares; and MS is mean of squares. 


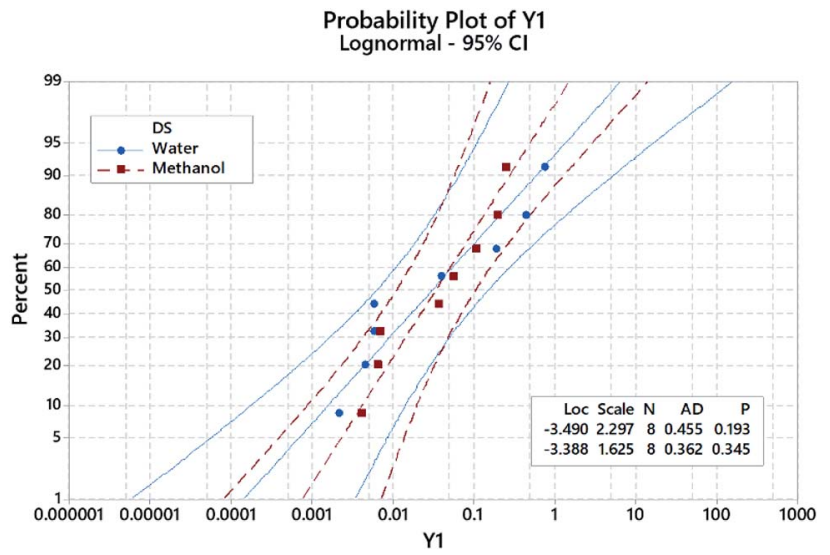

Fig. 4 Probability plot for the absorbance of the NBD-derivative measured at $469 \mathrm{~nm}$ following response transformation. Data points were grouped according to the employed diluting solvent, DS. The external lines on the graph are confidence intervals for the individual percentiles. Lognormal data distribution fitting was implemented.

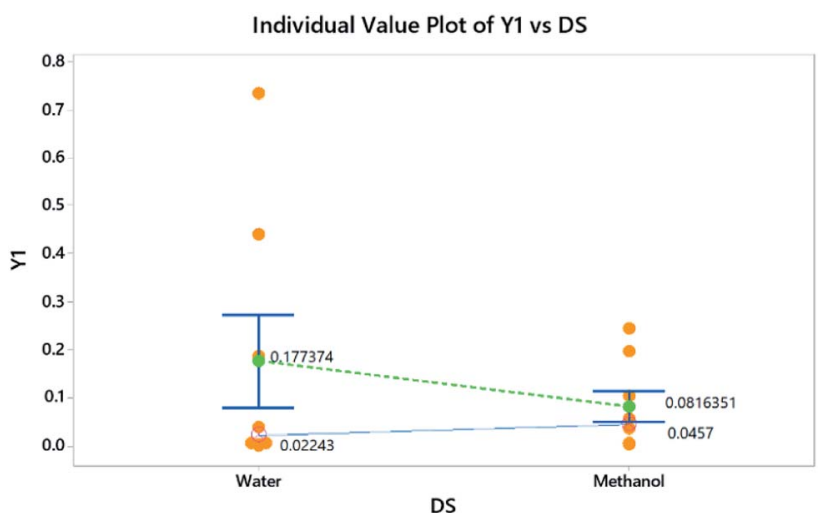

Fig. 5 Individual value plot with added interval bars at $95.0 \mathrm{Cl}$.

Aldrich, Germany and used without further purification. Now Foods ${ }^{\circledR}$ dietary supplement capsules (500 mg ORN per capsule) were purchased from a local hypermarket, Doha, Qatar.

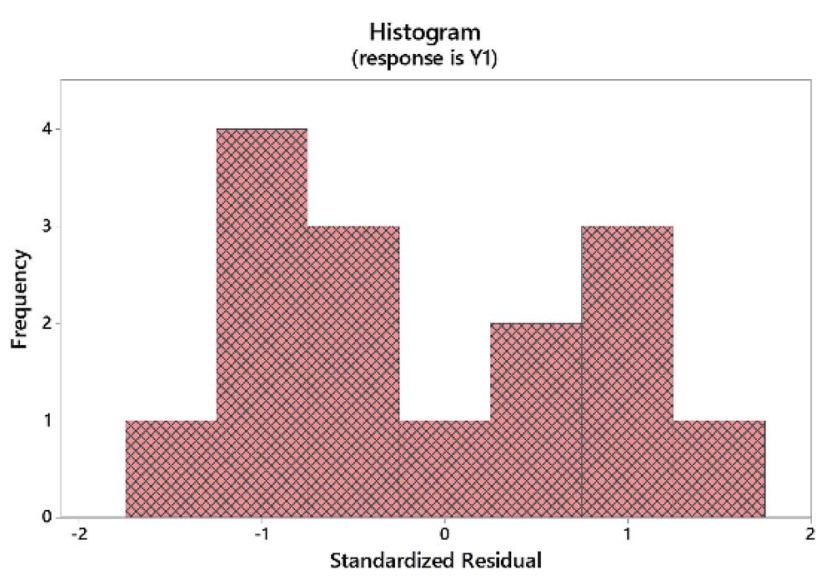

Fig. 6 Histogram plot.
Table 4 Descriptive statistics for the 2-sample $t$-test ${ }^{a}$

\begin{tabular}{|c|c|c|c|c|c|}
\hline Response variable & $\begin{array}{l}\text { Solvent } \\
\text { type }\end{array}$ & $N$ & Mean & SD & SE mean \\
\hline \multirow[t]{2}{*}{ Transformed response } & Water & 8 & 0.177 & 0.272 & 0.096 \\
\hline & Methanol & 8 & 0.0816 & 0.0927 & 0.033 \\
\hline
\end{tabular}

\subsection{Reagents and standards}

Stock solutions of $\mathrm{L}_{-} \mathrm{ORN}$ and NBD-Cl $\left(1 \mathrm{mg} \mathrm{mL}^{-1}\right)$ in distilled water (DW) and in methanol, respectively, were freshly prepared on site. Serial dilutions were prepared in the same solvents. Several solutions of borate buffer with a $\mathrm{pH}$ range of 7-11 were prepared by using a mixture of $\left(\mathrm{Na}_{2} \mathrm{~B}_{4} \mathrm{O}_{7} \cdot 10 \mathrm{H}_{2} \mathrm{O}\right)$ and $0.1 \mathrm{M}$ $\mathrm{NaOH}$ or $0.1 \mathrm{M} \mathrm{HCl}$. To prepare $50 \mathrm{mM}$ of $\left(\mathrm{Na}_{2} \mathrm{~B}_{4} \mathrm{O}_{7} \cdot 10 \mathrm{H}_{2} \mathrm{O}\right)$, $4.767 \mathrm{~g}$ was dissolved in $250 \mathrm{~mL} \mathrm{DW.}{ }^{20}$

\subsection{General procedure}

2.4.1 Procedure for the bulk powder: screening phase of the experimental design. The variables to be investigated and their levels are shown in Table 1. A set of 16 runs was performed in two blocks, one replicate with 4 added central points. Aliquots of the drug stock solution were transferred to a series of 16 test tubes, followed by $1 \mathrm{~mL}$ of the buffer solution and the specified volume of the reagent according to the experimental setup shown in Table 2. Solutions were heated to the temperature needed during a specific reaction time. Solutions were cooled down, transferred to $10 \mathrm{~mL}$ volumetric flasks and the volume was completed to the mark with an appropriate diluting solvent as shown in Table 2. Finally, the absorbance of the yellow solutions was measured at $469 \mathrm{~nm}$ against a blank for each sample which is similarly prepared by omitting L-ORN.

2.4.2 Procedure of dietary supplements. Ten capsules were emptied and finely powdered in a mortar. A quantity of the powder equivalent to $100 \mathrm{mg}$ of $\mathrm{L}_{\mathrm{L}} \mathrm{ORN}$ was then dissolved in $100 \mathrm{~mL}$ DW. The obtained solution was then filtered, and the filtrate was transferred into a $100 \mathrm{~mL}$ volumetric flask and the volume was made up to the mark using the same solvent. The procedure was completed following the outlined steps under the general procedure and by implementing the optimal conditions as will be shown later.

2.4.3 Procedure of the calibration curve for the drug and dietary supplement. To construct the calibration curve of $\mathrm{L}^{-}$ ORN, different volumes with final concentrations of 5-50 $\mu \mathrm{g}$ $\mathrm{mL}^{-1}$ were used. Optimum conditions were followed. The same procedure was applied for the formulation solution.

2.4.4 Procedure for the standard addition method. Seven samples were prepared by adding $300 \mu \mathrm{L}$ of the formulation to each test tube (labelled from F0-F6). Then, the solution of the drug was added in 8 different volumes starting from F1 $100 \mu \mathrm{L}$ till F6 $600 \mu \mathrm{L}$. The buffer and the reagent were added according to the optimum conditions. The absorbance of the samples was measured against a blank following the general procedures and by applying optimal conditions. 


\section{Cube Plot (fitted means) for Y1}

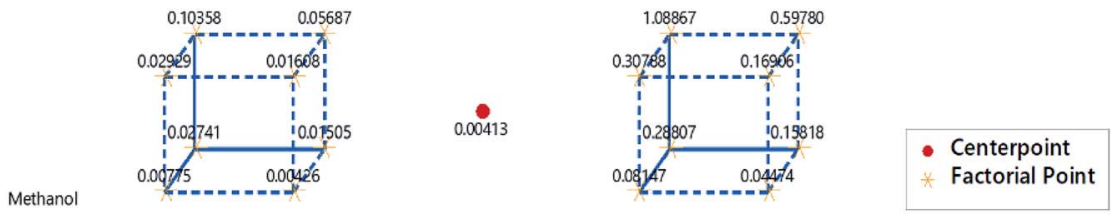

DS

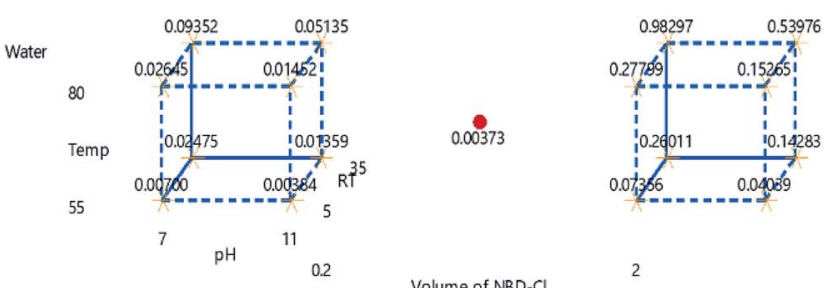

Fig. 7 Cube plot for the fitted means of $Y 1$ of the L-ORN-NBD-Cl reaction product.

2.4.5 Procedure for Job's technique. Equimolar concentrations $(0.0075 \mathrm{M})$ of $\mathrm{L}-\mathrm{ORN}$ and $\mathrm{NBD}-\mathrm{Cl}$ were prepared in order to investigate the molar ratio. The total volume was set as $5 \mathrm{~mL}$. Samples were similarly prepared under the optimal conditions. Methanol was added to each volumetric flask to complete the volume to $10 \mathrm{~mL}$. Finally, the absorbance was measured for each sample against its own blank. ${ }^{21}$

\section{Results and discussion}

\subsection{Nucleophilic substitution reaction (SN2)}

In general, the detection of amines and amino acids needs a derivatization step. The main goal of that step is to increase the detection limit at these conditions. NBD-Cl, a commonly used derivatizing agent, has an absorption maximum at 342 nm. ${ }^{12-14}$

NBD-Cl generally reacts with primary and secondary amines to produce an NBD-product. The general mechanism for this reaction is shown in Scheme 3. The proposed mechanism shows that the chlorine atom in position 7 of the aromatic ring is attacked by the amine group which acts as a nucleophile. This reaction could be performed in basic reaction media. ${ }^{\mathbf{1 2 - 1 5}}$

NBD-Cl derivatives are the products of nucleophilic aromatic substitution which occurs when a nucleophile displaces a good leaving group. ${ }^{22}$ L-ORN has two amine groups, which act as nucleophiles while the NBD-Cl has a chlorine atom, which is a good leaving group. Therefore, under the optimum conditions, the nucleophilic substitution reaction takes place and the response is recorded as $Y 1$.

Absorption spectra of both L-ORN, NBD-Cl, and their reaction product were measured against reagent blanks. L-ORN does not possess a chromophore moiety and therefore absorbs in the UV region, an issue that might cause an interference from the co-formulated excipients and adjuvants in case it is determined directly without derivatization.

As shown in Fig. 1, the formed yellow coloured product has a maximum absorbance at $469 \mathrm{~nm}$ (red shift). It has been noticed that for some samples when the $\mathrm{pH}$ value is high, two peaks were obtained. The first peak might be attributed to formation of the SN2 product at $469 \mathrm{~nm}$. This peak and with the

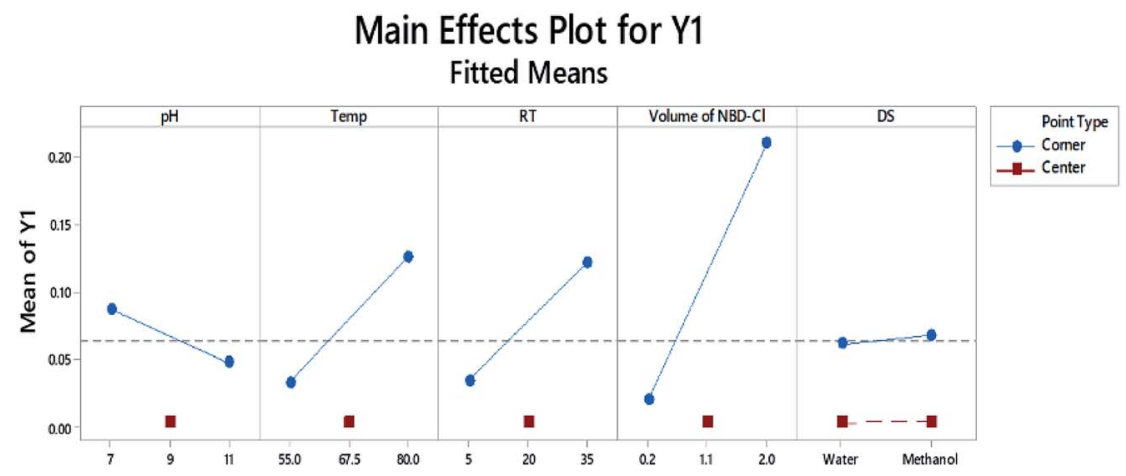

Fig. 8 Main effects plot using PBD and following response transformation. 


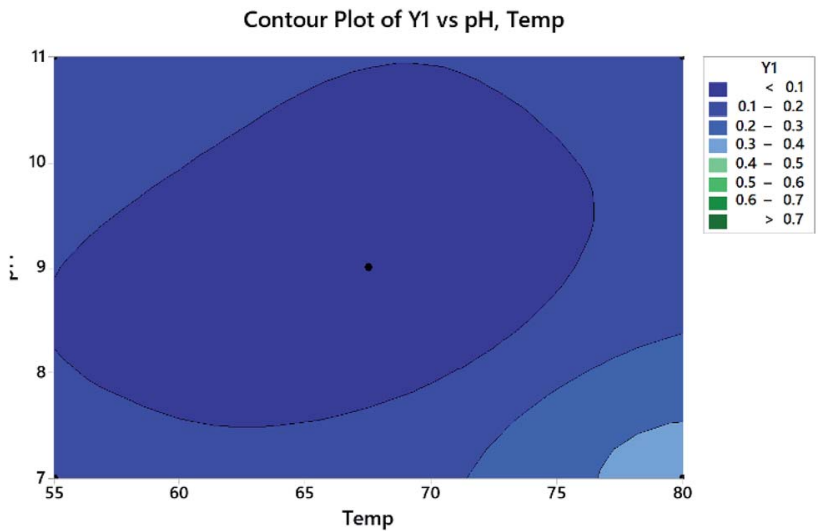

Surface Plot of $\mathrm{Y} 1 \mathrm{vs} \mathrm{pH}$, Temp

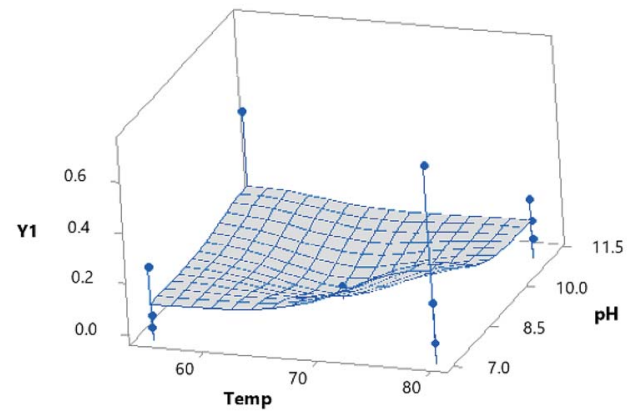

Fig. 9 Two-dimensional (2D) contour and three-dimensional (3D) surface plots.

excess of $\mathrm{OH}^{-}$in the solution would decompose and another peak starts to form at $500 \mathrm{~nm}$. The latter can be attributed to the hydrolysis of NBD-Cl at high $\mathrm{pH}$ and the formation of NBD$\mathrm{OH} .{ }^{23}$ The latter product might cause a high background necessitating the acidification of the reaction mixture.
Table 5 Analytical parameters for the determination of L-ORN

\begin{tabular}{llll}
\hline Parameter & Value & Parameter & Value \\
\hline Wavelength, $\lambda_{\max }(\mathrm{nm})$ & 469 & Slope $(b)$ & 0.0180 \\
Linear range, $\left.(\mu \mathrm{g} \mathrm{mL})^{-1}\right)^{a}$ & $5.00-50.00$ & Intercept $(a)$ & 0.1036 \\
$S_{b}$ & $2.41 \times 10^{-4}$ & $r^{2}$ & 0.9991 \\
$\pm \mathrm{t} S_{b}$ & $1.67 \times 10^{-4}$ & LOD $\left.(\mu \mathrm{g} \mathrm{mL})^{-1}\right)^{b}$ & 1.77 \\
$S_{a}$ & $6.90 \times 10^{-3}$ & LOQ $(\mu \mathrm{g} \mathrm{mL})^{b}$ & 5.38 \\
$\pm \mathrm{t} S_{a}$ & $4.78 \times 10^{-3}$ & Residual SS & $4.70 \times 10^{-4}$ \\
$S_{y / x}$ & $9.69 \times 10^{-3}$ & Regression SS & 0.5257
\end{tabular}

${ }^{a}$ Regression equation: $Y=b X+a$, where $Y$ is the absorbance, $X$ is concentration in $M, a$ is the intercept, $b$ is the slope, $S_{b}=\mathrm{SD}$ of slope, $\pm t S_{b}=$ confidence limit for slope, $S_{a}=\mathrm{SD}$ of intercept $\pm t S_{a}=$ confidence limit for intercept $S_{y / x}=\mathrm{SD}$ of the regression, SS is sum of squares. ${ }^{b}$ LOD $=$ limit of detection, LOQ $=$ limit of quantification, and $r^{2}=$ coefficient of determination.

Furthermore, this product was not stable. This could be attributed to the increase in the rate of the backward reaction as the $\left[\mathrm{OH}^{-}\right]$increases, which in turn could be due to a possible competition between $\mathrm{OH}^{-}$and the formed nucleophile, Fig. 2 .

\subsection{Assessments of reaction conditions}

3.2.1 Assessment of the variables' impact. Predicted values of the response before and after the response transformation are shown in Table 2. Approximately all the values of the predicted responses following the transformation employing the Box-Cox transformation are close to the measured (experimental) values. The optimal value of $\lambda$ (transformation factor, determined from Box-Cox transformation plots, figures are not shown) was 0 with a confidence interval (CI) of $95.0 \%$. The regression equation is presented as:

$$
\ln (Y 1)=-7.26-0.1499 \mathrm{pH}+0.0532 \mathrm{Temp}+0.0421 \mathrm{RT}+
$$

1.307 volume of NBD-Cl + 0.051 DS $-2.801 \mathrm{Ct} \mathrm{Pt}$

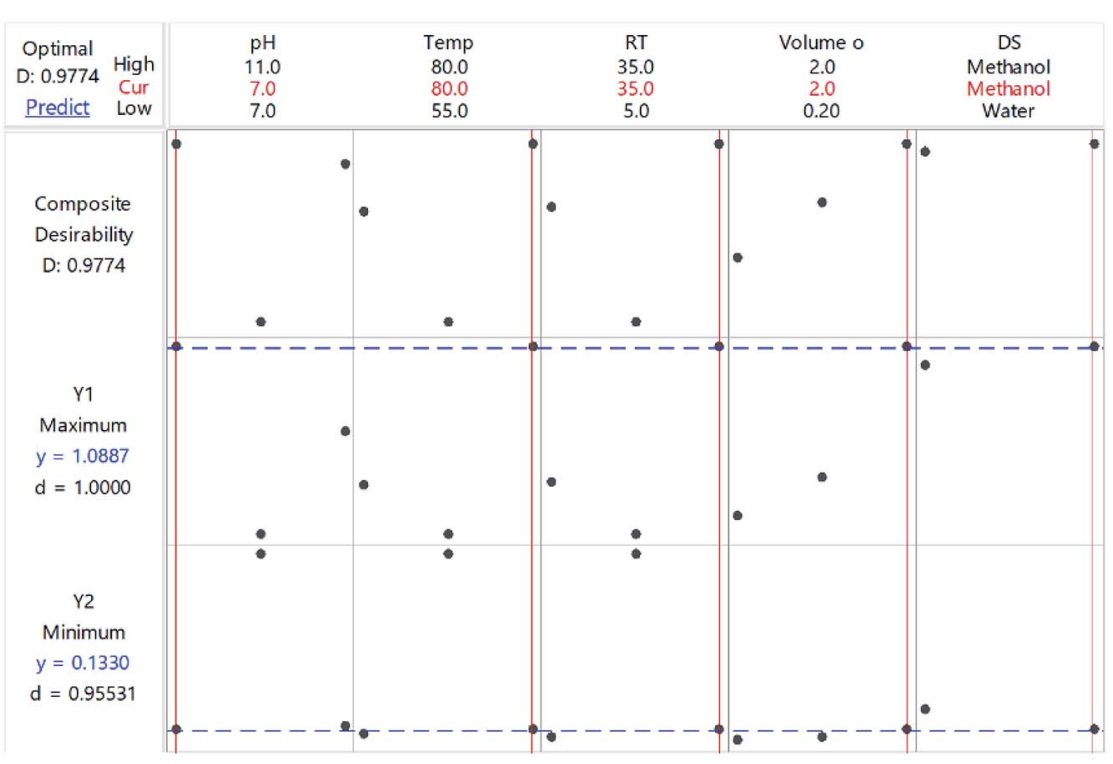

Fig. 10 Desirability plots. 
Table 6 Determination of L-ORN in the authentic form and in formulations using the optimized procedure. The table shows the inter- and intraday assays for L-ORN in its pure form as well as in the formulation. Direct calibration and standard addition methods were performed

Taken $\left(\mu \mathrm{g} \mathrm{mL}^{-1}\right) \quad$ Found $\left(\mu \mathrm{g} \mathrm{mL}^{-1}\right) \quad \%$ recovery

\section{Determination of L-ORN in bulk powder}

$\begin{array}{ll}5.00 & 4.97 \\ 10.00 & 9.97 \\ 15.00 & 14.66 \\ 20.00 & 20.18 \\ 30.00 & 30.08 \\ 40.00 & 40.91 \\ 50.00 & 49.32 \\ \text { Mean }^{a} \pm \mathrm{SD} & 99.84 \pm 1.49 \\ \text { RSD } & 1.494\end{array}$

99.33

99.67

97.76

100.9

100.3

100.3

98.63

$99.84 \pm 1.49$

RSD

Determination of $\mathrm{L}-\mathrm{ORN}$ in formulations (Now Foods ${ }^{\circledR}$ capsules): direct calibration method

\begin{tabular}{llr}
10.00 & 9.97 & 99.67 \\
15.00 & 14.68 & 97.87 \\
20.00 & 20.08 & 100.4 \\
30.00 & 30.61 & 102.0 \\
40.00 & 40.63 & 101.6 \\
50.00 & 49.55 & 99.10 \\
$\operatorname{Mean}^{a} \pm$ SD & $100.10 \pm 1.55$ & \\
RSD & 1.55 & \\
\hline
\end{tabular}

Taken $\left(\mu \mathrm{g} \mathrm{mL}{ }^{-1}\right)$ Added $\left(\mu \mathrm{g} \mathrm{mL} \mathrm{L}^{-1}\right)$

$\%$ recovery $^{a}$

Determination of $\mathrm{L}_{-}-\mathrm{ORN}$ in formulations (Now Foods ${ }^{\circledR}$ capsules): standard addition method

15.00

15.00

15.00

15.00

15.00

15.00

15.00

$\operatorname{Mean}^{a} \pm \mathrm{SD}$

RSD

$\begin{array}{lc}- & 99.96 \\ 5 & 99.60 \\ 10 & 100.1 \\ 15 & 101.1 \\ 20 & 101.4 \\ 30 & 102.61 \\ 35 & 101.76 \\ 100.93 \pm 1.01 & \\ 1.09 & \end{array}$

Concentration $\left(\mu \mathrm{g} \mathrm{mL}{ }^{-1}\right)$

Mean $\%$ recovery $^{a} \pm \mathrm{SD}$

Error (\%)

Inter and intra-day precision for determination of $\mathrm{L}_{\mathrm{L}} \mathrm{ORN}$ in bulk powder

(a) Inter-day

20.00

30.00

50.00

$99.38 \pm 1.21$

$98.00 \pm 0.70$

0.62

$100.3 \pm 1.1$

0.87

(b) Intra-day

20.00

30.00

$99.70 \pm 0.75$

0.30

$99.53 \pm 1.04$

0.47

50.00

$99.04 \pm 1.06$

0.96

Inter and intra-day precision for determination of Now Foods ${ }^{\circledR}$ capsules

(a) Inter-day

10.00

40.00

50.00

$100.2 \pm 0.6$

$-0.23$

$98.28 \pm 1.62$

1.72

(b) Intra-day

10.00

$99.53 \pm 1.50$

0.47

40.00

$100.33 \pm 0.76$

$-0.33$

$98.97 \pm 1.00$

0.45

$99.55 \pm 1.09$

1.03

${ }^{a}$ Mean \pm SD of 3 determinations. (a) The intra-day $(n=3)$ average of three concentrations of $\mathrm{L}$-Ornithine repeated three times within the same day. (b) The inter-day $(n=3)$ average of three concentrations of L-ORN repeated three times in three different days.

$R^{2}=97.98 \%, R^{2}$-adj $=96.63 \%$, and $R^{2}$-pred $=92.71 \%$.

The value of $R^{2}$ was high, signifying the linearity of data. The value of $R^{2}$-predicted was close to that of $R^{2}$, inferring that the model was not over-fitted, and high, implying the capability of the model to predict the absorbance values for new experiments. The Pareto chart, Fig. 3, illustrates which factors had an impact on the 
Table 7 Results obtained by the proposed methods for the determination of L-ORN using NBD-Cl in authentic form and in pharmaceutical preparation compared to the reported method $^{11}$

\begin{tabular}{llll}
\hline Parameter & Proposed method & Reported method ${ }^{11}$ & $\begin{array}{l}\text { Now Foods }{ }^{\circledR} \\
\text { capsules }\end{array}$ \\
\cline { 2 - 2 }${ }^{a}$ & 99.84 & 98.69 & 100.9 \\
$\pm \mathrm{SD}$ & 1.491 & 1.56 & 1.10 \\
$\mathrm{RSD}$ & 1.494 & 1.58 & 1.09 \\
$V$ & 2.22 & 2.13 & 1.21 \\
$n$ & 7 & 3 & 6 \\
$\pm \mathrm{SE}$ & 0.564 & 0.400 & 0.450 \\
$t$-value & $1.083(2.262)^{\mathrm{a}}$ & & \\
$F$ & $1.04(19.3)^{\mathrm{b}}$ & & \\
${ }^{a}$ Average of 3 determinations; ${ }^{\mathrm{a}}$ and $^{\mathrm{b}}$ are the tabulated $t$-values and $F$ - \\
ratios at $p=0.05$.
\end{tabular}

measured absorbance values. Three factors were found to be statistically significant; Temp, RT, and RV, and the latter was the most effective. All the results that were obtained from the Pareto chart were further confirmed using the analysis of variance (ANOVA), Table 3 , where any factor that has a $p$ value that exceeds 0.05 implies that the data do not fit the null hypothesis. ${ }^{17,18,24-28}$

3.2.2 Data modeling. Following data transformation, the distribution of data was investigated employing probability plots at 95.0\% CI, Fig. 4. As shown, DS was used for grouping data. The obtained $p$-values were higher than the significance level $(\alpha=0.05)$. Moreover, the data obtained followed the fitted line well. The individual value plot, Fig. 5, was used to assess data coverage and the existence of outliers. Fig. 5 shows that few outliers exist specially when using water as DS, though the data mean and median were a bit higher compared to methanol as DS.

Similarly, histograms (residual plots) were used to check the normality of the data. The histogram in Fig. 6 shows a bimodal distribution (data with 2 peaks, without categorization). A 2sample $t$-test was further used to evaluate the influence of different DS on the absorbance of the NBD-derivative. Results showed that there is no significant difference between both solvents where $P$-value $>$ significance level $(\alpha)$. Descriptive statistics are shown in Table 4. This finding further confirms that the impact of DS as shown in Fig. 3 is not statistically significant. In the same itinerary, normal probability plots are used to attest whether the data are linear or normally distributed, Fig. 4. Two parameters were used to check the linearity of the data; $p$ - and Anderson-Darling (AD) values. The obtained data shows that goodness-of-fit was achieved..$^{29,30}$

3.2.3 Model analysis. Cube plots are an efficient way that is used to investigate the influence of the main effects on the response. ${ }^{31}$ As seen in Fig. 7, four cubes display all the possible blends of factorial settings, where each variable is set to two levels; lower bound and upper bound. Cubes a and $\mathrm{b}$ (the left and right upper panels, respectively) represent the response means when the DS is methanol, and the volume of NBD-Cl is set to its lower bound (left cube) or highest level (right cube). To assess the model predictions of fitted means, all points of the design would be tested. For example, the combination of the volume of NBD-Cl of $2 \mathrm{~mL}, \mathrm{pH}$
7, DS methanol, RT $35 \mathrm{~min}$, and Temp $80{ }^{\circ} \mathrm{C}$ is associated with the highest fitted mean of $Y 1$ (1.08867).

The main effects plot in Fig. 8 illustrates how the factors are affecting the response. Each effect is represented by a line, and the steeper the line, the greater the influence of this variable. As shown, almost all the factors' lines are not horizontal. The $\mathrm{pH}$ has a negative effect on the response, compared to the positive impact exerted by RT, Temp and RV.

3.2.4 Optimization phase plots. Contour plots (2D) and surface plots (3D) were used to illustrate the relationship between three variables. Two factors are plotted on the $x$-axis and $y$-axis and the response is on the $z$-axis. As seen in Fig. 9, Abs. values of 0.1-0.2 are obtained using Temp between $55-72{ }^{\circ} \mathrm{C}$ and $\mathrm{pH} 7-8$. The combination between the three axes produces valleys and peaks labelled as local minima and local maxima, respectively. As seen in the lower panel in Fig. 9, the two factors that were studied are Temp with $\mathrm{pH}$. A local maximum is obtained when the Temp is $67.5^{\circ} \mathrm{C}$ and $\mathrm{pH}$ is between $8.5-10$, while the local minimum is produced when Temp is $80^{\circ} \mathrm{C}$ and $\mathrm{pH}$ is 7 .

The optimization plot is shown in Fig. 10 and illustrates the optimum conditions. The purpose was to maximize the absorbance measured at $469 \mathrm{~nm}(Y 1)$ and minimize the absorbance of the NBD-OH adduct at $500 \mathrm{~nm}(Y 2)$. Fig. 9 shows the $d$-value (individual desirability function) for $Y 1$ and $Y 2$ and $D$-value (composite desirability function). The vertical red lines represent the optimal conditions for each factor. The blue dashed line represents the responses. The optimum conditions that were determined from the combination of the two responses are $\mathrm{pH}=7, \mathrm{Temp}=80^{\circ} \mathrm{C}, \mathrm{RT}=35 \mathrm{~min}, \mathrm{NBD}-\mathrm{Cl}$ volume $=2 \mathrm{~mL}$ and methanol is DS.

\subsection{Stoichiometry}

The results of Job's technique of continuous variation shows that the highest absorbance was achieved at a mole fraction of $0.35(D): 0.65$ (NBD-Cl), implying a molar ratio of $1(D): 2$ (NBD$\mathrm{Cl})$. Therefore, it can be concluded that the two amine moieties might have been involved in the reaction.

\subsection{Validation}

The analytical parameters are listed in Table 5. According to the ICH guidelines, the proposed method was evaluated considering the following items and as will be revealed in the following subsections. ${ }^{32}$

3.4.1 Linearity range. Calibration curves that were obtained from the measurement of the response of the drug and the formulation against the concentration show a linear relationship in the range of $5-50 \mu \mathrm{gL}^{-1}$. The regression equation is:

$$
Y_{\text {pure drug }}=0.0180 X+0.1036 R^{2}=0.9991
$$

3.4.2 Accuracy and precision. The \% relative standard deviation, RSD\% was found to be less than $5 \%$ with a confidence interval (CI) of $95.0 \%$. The precision was evaluated three times a day for each sample (intra-days) or during three different days (inter-day). The results shown in Tables 6 and 7 
indicate a high precision with low values of standard deviation (SD). Moreover, all the recovery values shown in Tables 6 and 7 are more than $95.00 \%$ with a low percentage of error, which indicates that this method is accurate.

3.4.3 Specificity. The impact of common additives and excipients on the specificity of the proposed approach was evaluated via applying the proposed technique on the marketed capsules either directly or after the standard addition. The results show that there was no interference from commonly formulated adjuvants, as revealed by elevated recoveries and low values of standard deviations, Table 6 .

3.4.4 Limit of detection (LOD) and limit of quantification (LOQ). LOD and LOQ were calculated using the following equations:

$$
\mathrm{LOD}=3.3 \frac{\mathrm{SD}}{s}, \mathrm{LOQ}=10 \frac{\mathrm{SD}}{\mathrm{s}}
$$

where $s$ is the slope of the calibration curve and SD the standard deviation of the blank ( 5 measurements). Values of LOD and LOQ are shown in Table 5. This method is showing high sensitivity for the determination of L-ORN.

3.4.5 Robustness. Though the implemented factorial design, PBD, is known as a robustness test, the current approach robustness was studied by testing the impact of slight variations in the procedure variables on the measured absorbance at $469 \mathrm{~nm}$. Therefore, the consequence of insignificant variations in the following factors, $\mathrm{pH}$, volume of $\mathrm{NBD}-\mathrm{Cl}$, Temp, RT and DS, was tested. Changes were done as follows: $\mathrm{pH} \pm 0.2$ units, Temp $\pm 5{ }^{\circ} \mathrm{C}, \mathrm{RT} \pm 10 \mathrm{~min}$; volume of $\mathrm{NBD}-\mathrm{Cl} \pm$ $0.5 \mathrm{~mL}$, and DS (water and methanol). The impact of these variations was irrelevant where $\mathrm{RSD} \%$ did not surpass $1.20 \%$.

3.4.6 Stability of the NBD-product. The formed product was left at room temperature for periods up to $24 \mathrm{~h}$. The reaction product was found to be stable for the tested time periods with a decrease in absorbance which did not exceed $2 \%$ of the measured original absorbance value, indicating the high stability of the reaction product.

\section{Conclusions}

L-ORN was analyzed in its pure form and in its dietary supplements using a spectrochemical approach. A nucleophilic substitution reaction was pathway taken to derivatize L-ORN using NBD-Cl. A single response (absorbance at $469 \mathrm{~nm}$ ) was measured as a function of five variables using a multivariateassisted strategy. PBD was used as an experimental design for the screening phase. Pareto charts and ANOVA techniques were used to determine the factors that have an impact on the response. Factorial levels were adjusted to give the maximum response. The molar ratio was determined to be $(2: 1)$ (reagent : drug) using Job's technique. Finally, and using ICH guidelines, the proposed method was validated.

\section{Conflicts of interest}

There are no conflicts to declare.

\section{Acknowledgements}

This work was made possible by student grant [QUST-1-CAS2019-13] from Qatar University. The statements made herein are solely the responsibility of the authors. The authors would like to thank Dr Mohanad Shkoor, Department of Chemistry and Earth Sciences, College of Arts and Sciences, Qatar University for his helpful advice on establishing the reaction mechanism.

\section{References}

1 OJL, Directive 2002/46/Ec, The European Parliament and of The Council, 2002, vol. 183, pp. 51-57.

2 Y. Motarjemi and H. Lelieveld, in A Practical Guide for the Food Industry, ed. Y. Motarjemi and H. Lelieveld, Academic Press, San Diego, 1st edn, 2014, ch. 47, pp. 1127-1130.

3 M. Sivashanmugam, J. Jaidev, V. Umashankar and K. N. Sulochana, Biomed. Pharmacother., 2017, 86, 185-194. 4 B. Zhang, L. Ren, M. Yu, Y. Zhou and B. Ye, Bioresour. Technol., 2018, 250, 60-68.

5 R. C. Benson, K. A. Hardy and C. R. Morris, J. Allergy, 2011, 2011, 1-12.

6 M. Williams, J. Int. Soc. Sports Nutr., 2005, 2, 63-67.

7 J. A. Chromiak and J. Antonio, Nutrition, 2002, 18, 657-661.

8 Y. Fujimura and M. Kawamura, Clin. Chim. Acta, 1996, 253, 1-8.

9 L. H. de Jonge and M. Breuer, J. Chromatogr. B: Biomed. Sci. Appl., 1996, 677, 61-68.

10 P. Kowalski, M. Bieniecki, I. Ol $\square$ dzka and H. Lamparczyk, Biomed. Chromatogr., 2006, 20(2), 185-194.

11 M. S. Elazazy, M. El-Hamshary, M. Sakr and H. S. Al-Easa, Spectrochim. Acta, Part A, 2018, 193, 397-406.

12 A. F. Akinyele, J. I. Okogun and O. P. Faboya, J. Agric. Food Chem., 1999, 47, 2303-2307.

13 M. A. Omar, M. A. Hammad and M. Awad, RSC Adv., 2017, 7, 44773-44779.

14 A. A. Elbashir, F. E. O. Suliman and H. Y. Aboul-Enein, J. Fac. Pharm. Gazi Univ., 2011, 24, 679-697.

15 F. Orata, in Advanced Gas Chromatography - Progress in Agricultural, Biomedical and Industrial Applications, ed. M. A. Mohd, InTech, 2012, ch. 5, pp. 83-108.

16 R. Leardi, Anal. Chim. Acta, 2009, 652, 161-172.

17 R. L. Plackett and J. P. Burman, Biometrika, 1946, 33, 305325.

18 M. S. Elazazy, in Spectroscopic Analyses - Developments and Applications, ed. E. Sharmin and F. Zafar, IntechOpen, 69891, 2017, ch. 11, pp. 213-230.

19 P. W. Araujo and R. G. Brereton, Trends Anal. Chem., 1996, 15, 26-31.

20 T. Kaneta, in Capillary Electrophoresis of Proteins and Peptides: Methods and Protocols, ed. N. T. Tran and M. Taverna, Springer New York, New York, NY, 2016, ch. 2, pp. 11-23.

21 P. Job, Ann. Chim., 1928, 9, 113-203.

22 K. Gbayo, C. Isanbor, K. Lobb and O. Oloba-Whenu, Phys. Sci. Rev., 2017, 2, 1-6. 
23 A. Önal, Quim. Nova, 2010, 34, 677-682.

24 G. E. P. Box and D. A. Cox, J. R. Stat. Soc. Series B Stat. Methodol., 1964, 26, 211-252.

25 M. Bicego and S. Baldo, Neurocomputing, 2016, 218, 390-400.

26 A. H. Bademlioglu, A. S. Canbolat, N. Yamankaradeniz and O. Kaynakli, Appl. Therm. Eng., 2018, 145, 221-228.

27 M. S. Elazazy, K. Ganesh, V. Sivakumar and Y. H. A. Huessein, RSC Adv. , 2016, 6, 64967-64976.

28 M. S. Elazazy, RSC Adv., 2015, 5, 48474-48483.
29 T. W. Anderson and D. A. Darling, J. Am. Stat. Assoc., 1954, 49, 765-769.

30 G. Marsaglia and J. C. W. Marsaglia, J. Stat. Softw., 2004, 9, 15.

31 M. J. Anderson and P. J. Whitcomb, DOE Simplified: Practical Tools for Effective Experimentation, CRC Press, 3rd edn, 2015.

32 International Conference on Harmonization, ICH Harmonized Tripartite Guideline - Validation of Analytical Procedures: text and methodology, Q2 (R1) Version 4, Fed. Register, 2005. 